\title{
Consumo, digestibilidade total, produção de proteína microbiana e balanço de nitrogênio em dietas para ruminantes de subprodutos
}

\author{
[Intake, total digestibility, microbial protein production, and the nitrogen balance in ruminant diets based on \\ agricultural and agro-industrial by-products] \\ J.A.G. Azevêdo ${ }^{1}$, S.C. Valadares Filho ${ }^{2}$, D.S. Pina ${ }^{3}$, R.F.D. Valadares ${ }^{4}$, E. Detmann ${ }^{2}$, \\ M.F. Paulino ${ }^{2}$, L.L. Diniz ${ }^{2}$, H.J. Fernandes ${ }^{5}$ \\ ${ }^{1}$ Departamento de Ciências Agrárias e Ambientais - UESC - Ilhéus, BA \\ ${ }^{2}$ Departamento de Zootecnia - UFV - Viçosa, MG \\ ${ }^{3}$ Departamento de Zootecnia - UFMT - Cuiabá, MT \\ ${ }^{4}$ Departamento de Medicina Veterinária - UFV - Viçosa, MG \\ ${ }^{5}$ Departamento de Zootecnia - UEMS - Campos Grande, MS
}

\begin{abstract}
RESUMO
Avaliaram-se os efeitos da inclusão da fonte - subproduto do cacau, mandioca-casca, mandioca-caule e farelo de glúten de milho - e da proporção - 10 e 30\% - de subprodutos, em substituição parcial à silagem de milho sobre consumo, digestibilidade dos nutrientes, produção de proteína microbiana, balanço de nitrogênio, predição das frações digestíveis e nutrientes digestíveis totais. Os consumos de matéria seca e de fibra em detergente neutro foram influenciados pela fonte de subproduto. A fonte de subproduto influiu na digestibilidade do extrato etéreo e dos carboidratos não fibrosos. O subproduto farelo de glúten de milho apresentou valor energético $17 \%$ maior do que a da silagem de milho, enquanto os da mandioca-casca, da mandioca-caule e do cacau apresentaram valores energéticos 10, 19 e 38\% menores do que o valor observado para silagem de milho. A fonte e o nível de subproduto não influíram na excreção urinária de derivados de purinas totais, de purinas absorvidas e de nitrogênio microbiano, e na eficiência microbiana. A fonte do subproduto influenciou a ingestão, a excreção nas fezes e na urina dos compostos nitrogenados e o balanço de nitrogênio. O farelo de glúten de milho e a mandioca-casca podem substituir, parcialmente, os concentrados energéticos, sem prejuízos para consumo, digestibilidade, eficiência microbiana e retenção de nitrogênio.
\end{abstract}

Palavras-chave: ruminante, alimento alternativo, resíduo agroindustrial, valor nutritivo

\begin{abstract}
The effects of inclusion of by-products (cocoa, cassava peel, cassava stalk, and corn gluten meal) and their levels (10 and 30\%), replacing part of corn silage on intake, digestibility of nutrients, microbial protein production, nitrogen balance, prediction of digestible fractions, and total digestible nutrients were evaluated. The intakes of dry matter and neutral detergent fiber were affected by source of byproduct, which affected the digestibility of ether extract and non-fibrous carbohydrates. The energy corn gluten meal was 17\% higher than that of corn silage, while the values for cassava peel, cocoa, and cassava stalk were 10,19, and 38\% lower than the value for corn silage. The source and the level of byproduct did not affect the urinary excretion of total purine, purine absorbed, microbial nitrogen, and microbial efficiency. The source of by-product affected intake, nitrogen compounds, excretion in feces and urine, and nitrogen balance. The corn gluten meal and cassava peel are by-products with potential to partly replace the energhetic concentrates, with no influence on the intake, digestibility, microbial efficiency, and nitrogen retention.
\end{abstract}

Keywords: alternative feed, agro-industrial waste, nutritional value

Recebido em 24 de abril de 2010

Aceito em 10 de janeiro de 2011

E-mail: augustog@uesc.br

Apoio: CNPq/ CT-AGRO/MCT, FAPEMIG e FAPESB 


\section{INTRODUÇÃO}

$\mathrm{Na}$ tentativa de minimizar os custos com a alimentação, cresce a utilização de fontes alimentares com melhor relação custo/benefício disponíveis regionalmente. Estima-se que só no estado da Bahia são gerados por ano, aproximadamente, 10 mil t de casca (tegumento) de cacau (CC) durante o processo industrial para obtenção do líquor (matéria-prima do chocolate), pois uma tonelada de amêndoa com $7 \%$ de umidade pode gerar de 80 a $120 \mathrm{~kg}$ de casca de cacau após o processamento (Sodré, 2008).

Os subprodutos da indústria da mandioca, como a casca, constituídos de cepas, pontas, cascas e películas, representam $4,5 \%$ do total de mandioca processada (Cereda, 1996). Além da mandioca-casca, outro subproduto da mandioca é o caule ou maniva gerado durante a colheita, em que, segundo Carvalho (1983), apenas 20\% são aproveitados para o replantio, ficando no campo $80 \%$.

No processo de beneficiamento do milho, são gerados diversos subprodutos, dentre esses o farelo de glúten de milho. Para cada $100 \mathrm{~kg}$ de milho em grãos, são produzidos 62 a $68 \mathrm{~kg}$ de amido, $3 \mathrm{~kg}$ de óleo, 3,2kg de farelo de gérmen, $20 \mathrm{~kg}$ de glúten e 4,5kg de farinha de glúten (Macedo et al., 2003). No entanto, como a composição química dos subprodutos agrícolas e agroindustriais não é homogênea, é preciso mais informações sobre a viabilidade do uso destes subprodutos na alimentação de bovinos. Este trabalho foi realizado com o objetivo de avaliar os efeitos da fonte e da proporção de subprodutos incluídos na dieta de ruminantes, sobre o consumo e a digestibilidade total de nutrientes, sobre a produção de proteína microbiana e sobre o balanço de nitrogênio, além da predição das frações digestíveis e nutrientes digestíveis totais destes subprodutos.

\section{MATERIAL E MÉTODOS}

Os subprodutos utilizados foram cacau, mandioca-casca, mandioca-caule e farelo de glúten de milho. O subproduto do cacau foi composto basicamente pelo tegumento que envolve a semente (amêndoa) após seu beneficiamento industrial, mas também continha pequenos pedaços de sementes. O subproduto mandioca-casca foi composto pela cepa, ponta, casca e entrecasca da raiz da mandioca resultante da pré-limpeza para fabricação da farinha de mandioca e foi seco em secador industrial a $60^{\circ} \mathrm{C}$. A mandioca-caule (maniva) foi composta apenas pelo caule da planta de mandioca desprovido de folhas e foi secada em secador industrial a $60^{\circ} \mathrm{C}$. O subproduto farelo de glúten de milho foi composto da parte da membrana externa do grão de milho que permanece após a extração da maior parte do amido, do glúten e do gérmen pelo processo empregado na produção do amido, ou do xarope por via úmida. A composição química da silagem de milho e dos subprodutos encontra-se na Tab. 1.

Tabela 1. Composição química da silagem de milho e dos subprodutos

\begin{tabular}{lccccc}
\hline Item & $\begin{array}{c}\text { Silagem de } \\
\text { milho }\end{array}$ & Cacau & $\begin{array}{c}\text { Farelo de } \\
\text { glúten }\end{array}$ & $\begin{array}{c}\text { Mandioca- } \\
\text { casca }\end{array}$ & $\begin{array}{c}\text { Mandioca- } \\
\text { caule }\end{array}$ \\
\hline MS $^{1}$ & 24,10 & 89,34 & 85,76 & 25,56 & 89,98 \\
MO $^{2}$ & 92,96 & 92,58 & 94,22 & 96,63 & 96,26 \\
PB $^{2}$ & 6,09 & 14,33 & 21,86 & 3,73 & 5,44 \\
PIDN $^{3}$ & 22,01 & 55,14 & 38,24 & 58,82 & 47,15 \\
PIDA $^{3}$ & 12,27 & 47,46 & 13,26 & 7,41 & 21,34 \\
EE $^{2}$ & 2,07 & 5,07 & 2,84 & 0,59 & 0,92 \\
FDNcp $^{2}$ & 56,07 & 36,97 & 22,68 & 15,75 & 65,11 \\
$\mathrm{CNF}^{2}$ & 28,73 & 36,22 & 46,84 & 76,56 & 24,79 \\
FDA $^{2}$ & 31,52 & 40,09 & 12,46 & 15,56 & 57,12 \\
$\mathrm{LIG}^{2}$ & 5,17 & 18,54 & 1,44 & 5,54 & 20,01 \\
\hline
\end{tabular}

1: \%; 2: \% na MS; 3: \% na PB.

MS: matéria seca; MO: matéria orgânica; PB: proteína bruta; PIDN: proteína insolúvel em detergente neutro; PIDA: proteína insolúvel em detergente ácido; EE: extrato etéreo; FDNcp: fibra em detergente neutro livre de cinza e proteína; CNF: carboidratos não fibrosos; FDA: fibra em detergente ácido; LIG: lignina. 
Todos os animais receberam duas vezes ao dia, ad libitum, com sobra possível de $10 \%$ no cocho, silagem de milho, mistura ureia/sulfato de amônio (9:1), para que as dietas se mantivessem isonitrogenadas, e suplemento mineral (Tab. 2).
As dietas foram formuladas para conter 10 e $30 \%$ de subprodutos na base da matéria seca (MS). Cada tratamento foi representado por uma fonte e uma proporção do subproduto na dieta.

Tabela 2. Proporção dos ingredientes e composição química das dietas, expressas com base na matéria seca

\begin{tabular}{|c|c|c|c|c|c|c|c|c|}
\hline \multirow{3}{*}{ Item } & \multicolumn{8}{|c|}{ Subproduto (\%) } \\
\hline & \multicolumn{2}{|c|}{ Cacau } & \multicolumn{2}{|c|}{$\begin{array}{l}\text { Farelo de } \\
\text { glúten }\end{array}$} & \multicolumn{2}{|c|}{ Mandioca-casca } & \multicolumn{2}{|c|}{ Mandioca-caule } \\
\hline & 10,95 & 31,24 & 10,47 & 31,09 & 10,54 & 30,25 & 10,53 & 30,77 \\
\hline \multicolumn{9}{|c|}{ Proporção do ingrediente (\%) } \\
\hline Silagem de milho & 86,78 & 66,30 & 86,86 & 67,50 & 85,82 & 66,19 & 85,96 & 65,94 \\
\hline Uréia & 1,14 & 1,31 & 1,50 & 0,37 & 2,38 & 2,30 & 2,26 & 2,06 \\
\hline Sulfato de amônia & 0,13 & 0,15 & 0,17 & 0,04 & 0,26 & 0,26 & 0,25 & 0,23 \\
\hline Sal mineral $^{1}$ & 1,00 & 1,00 & 1,00 & 1,00 & 1,00 & 1,00 & 1,00 & 1,00 \\
\hline \multicolumn{9}{|c|}{ Composição química (\%) } \\
\hline PB & 10,05 & 12,18 & 11,78 & 11,94 & 12,28 & 11,60 & 12,14 & 11,46 \\
\hline $\mathrm{EE}$ & 2,035 & 2,96 & 2,10 & 2,28 & 1,84 & 1,55 & 1,88 & 1,65 \\
\hline FDNcp & 52,71 & 48,73 & 51,08 & 44,90 & 49,78 & 41,88 & 55,05 & 57,01 \\
\hline $\mathrm{CNF}$ & 29,90 & 30,36 & 29,86 & 33,95 & 32,72 & 42,18 & 27,31 & 26,57 \\
\hline
\end{tabular}

PB: proteína bruta; EE: extrato etéreo; FDNcp: fibra em detergente neutro livre de cinza e proteína; CNF: carboidratos não fibrosos.

${ }^{1}$ Composição: $176 \mathrm{~g}$ de cálcio; $88 \mathrm{~g}$ de fósforo; $110 \mathrm{~g}$ de sódio; $5 \mathrm{~g}$ de magnésio; 12g de enxofre; 130mg de cobalto; 1200mg de cobre; 130mg de iodo; 1200mg de manganês; 15mg de selênio; 4000mg de zinco; 1200mg de ferro e 880mg flúor (máximo).

Foram utilizadas 16 novilhas, Nelore ou anelorada, em crescimento, com média de peso inicial de $280 \pm 38 \mathrm{~kg}$. Antes de iniciar o experimento, todos os animais foram pesados, identificados e tratados contra ecto e endoparasitas e, após a primeira pesagem, foram distribuídos, ao acaso, no tratamento. Os animais foram alojados em baias individuais cobertas, com piso revestido de borracha, de 3x3m de área, dotadas de comedouros e bebedouros individuais.

O consumo, os coeficientes de digestibilidade, a síntese de proteína microbiana e o balanço de nitrogênio foram avaliados em dois períodos experimentais. Em cada um dos dois períodos, avaliaram-se quatro subprodutos, com duração de 15 dias, sendo 12 dias de adaptação e três dias de coleta total de fezes, registrando-se a quantidade total excretada por animal. Durante a pesagem das fezes e após homogeneização, foram retiradas alíquotas de, aproximadamente, $5 \%$, para posterior confecção das amostras compostas de cada animal. Durante o período de coleta de fezes, foram registradas as quantidades de alimento consumido diariamente, coletando- se amostras dos alimentos oferecidos por tratamento e das sobras, por animal. Ao final do período experimental, todos os animais foram pesados.

Os coeficientes de digestibilidade dos nutrientes de cada subproduto foram estimados a partir dos coeficientes médios de digestibilidade das dietas específicas de cada tratamento, por sistema de equações lineares (Silva e Leão, 1979).

Todos os subprodutos coletados foram submetidos à pré-secagem a $60^{\circ} \mathrm{C}$ durante 72 horas e moídos em moinho de facas com peneira de porosidade de $1 \mathrm{~mm}$ de diâmetro, para posteriores análises do conteúdo de matéria seca (MS), proteína bruta (PB), matéria orgânica (MO), extrato etéreo (EE) e fibra em detergente ácido (FDA), conforme os métodos do AOAC (Official..., 1990).

Nas análises de fibra em detergente neutro (FDN), as amostras foram tratadas com alfaamilase termoestável, sem o uso de sulfito de sódio e corrigido para cinzas residuais (Mertens, 1992). A correção da FDN e FDA para os 
compostos nitrogenados e a estimação dos conteúdos de compostos nitrogenados insolúveis nos detergentes neutro (NIDN) e ácido (NIDA) foram feitas conforme Licitra et al. (1996). O conteúdo de lignina foi obtido por meio da solubilização da celulose pelo ácido sulfúrico (Van Soest e Robertson, 1985).

O conteúdo de carboidratos não fibrosos (CNF) dos subprodutos, expresso em \% na MS, foi calculado de acordo com Hall (2000) como: $100-(\% F D N+\% P B+\% E E+\% M M)$, e os nutrientes digestíveis totais (NDT) como: NDT $=$ \%PBdigestível + \%FDNdigestível + \%CNFdigestível + 2,25*\%EEdigestível.

As coletas totais de urina foram feitas nos mesmos dias das coletas de fezes, durante 72 horas consecutivas, utilizando-se cateteres de Folley número 22, duas vias, com balão de 30mL. Na extremidade livre da sonda, foi adaptada uma mangueira de polietileno, pela qual a urina foi conduzida até recipientes de plástico com tampa, contendo 500mL de ácido sulfúrico a $20 \%$.

Ao término de cada período de 24 horas de coleta, pesou-se o galão e homogeneizou-se o conteúdo e, então, coletaram-se amostras de $10 \mathrm{~mL}$, que foram pesados para determinação da densidade da urina e, posteriormente, com o peso total do galão menos sua tara e a densidade da urina, e determinação do volume total excretado, em litros.

Nas amostras de urina, foram realizadas as análises dos derivados de purinas (alantoína e ácido úrico) pelo método colorimétrico, conforme técnica de Fujihara et al. (1987), descrita por Chen e Gomes (1992).

Os subprodutos agrícolas e agroindustriais foram combinados em duas proporções - 10 e $30 \%$ na matéria seca -, com quatro repetições para cada proporção, a partir de um delineamento em reversão simples com fator adicional. Os mesmos quatro animais foram utilizados nas duas proporções do subproduto, no mesmo período, sendo que, no segundo período, os animais alimentados com dietas com menor porcentagem do subproduto receberam a proporção maior, e vice-versa.
Foram realizadas análises de variância e, quando necessário, compararam-se as médias, utilizandose o teste Tukey a $5 \%$ de probabilidade, com auxílio do programa SAS/2000.

\section{RESULTADOS E DISCUSSÃO}

Os consumos de PB, MS (em g/kg PV e $\mathrm{g} / \mathrm{kg} \quad \mathrm{PV}^{0,75}$ ) e FDN (em g/kg PV) foram influenciados $(\mathrm{P}<0,05)$ pela fonte de subproduto, independentemente da proporção de sua inclusão na dieta (Tab. 3). Os animais que receberam dietas com farelo de glúten de milho consumiram mais $\mathrm{PB} \quad(\mathrm{P}<0,05)$ em relação àqueles que consumiram dietas com subproduto do cacau e mandioca-caule, e os que consumiram dietas com mandioca-casca não diferiram $(\mathrm{P}>0,05)$ no consumo de $\mathrm{PB}$ em relação àqueles alimentados com dietas com farelo de glúten e mandiocacaule. Também não houve diferenças $(\mathrm{P}>0,05)$ entre as dietas subproduto do cacau e mandiocacaule quanto ao consumo de $\mathrm{PB}$.

Observou-se maior consumo de MS entre os animais que ingeriram dietas com farelo de glúten de milho em relação às dietas com os demais subprodutos, independentemente da porcentagem de inclusão desses subprodutos na dieta. Lassiter e Edwards (1982) relataram que o farelo de glúten de milho possui baixa palatabilidade, e Grande et al. (2003) não observaram diferenças no consumo (g/kg PV) entre tratamentos com farelo de soja como fonte de proteína para cabritos em crescimento.

Os animais alimentados com farelo de glúten de milho apresentaram maior $(\mathrm{P}<0,05)$ consumo de FDN (g/kg PV) em relação aos que consumiram subproduto cacau, contudo estes não diferiram $(\mathrm{P}>0,05)$ daqueles alimentados com mandiocacaule e mandioca-casca. O menor consumo de FDN entre os animais que receberam dietas com subproduto do cacau em relação àqueles que receberam dieta com farelo de glúten de milho foi consequência do menor consumo de MS total. Pires et al. (2005) observaram que a inclusão de $50 \%$ de farelo de cacau no concentrado reduziu o consumo de MS de novilhas e constataram lesões na pele, podendo ser consequência da teobromina. 
Tabela 3. Consumo de nutrientes em função da fonte (S) e da porcentagem (N) de inclusão de subprodutos à dieta

\begin{tabular}{|c|c|c|c|c|c|c|c|c|c|c|}
\hline \multirow[b]{2}{*}{ Item } & \multicolumn{4}{|c|}{ Subproduto } & \multicolumn{2}{|c|}{ Inclusão (\%) } & \multicolumn{3}{|c|}{ Valor P } & \multirow[b]{2}{*}{$\begin{array}{l}\mathrm{CV} \\
(\%)\end{array}$} \\
\hline & Cacau & $\begin{array}{c}\text { Farelo } \\
\text { de glúten }\end{array}$ & $\begin{array}{c}\text { Mandioca- } \\
\text { casca }\end{array}$ & $\begin{array}{l}\text { Mandioca- } \\
\text { caule }\end{array}$ & 10 & 30 & S & $\mathrm{N}$ & $\mathrm{S} \times \mathrm{N}$ & \\
\hline \multicolumn{11}{|c|}{ Consumo (kg/dia) } \\
\hline MS & 4,37 & 5,64 & 4,79 & 4,33 & 4,81 & 4,75 & 0,0007 & 0,4184 & 0,0429 & 11,8 \\
\hline MO & 3,92 & 5,45 & 4,50 & 4,09 & 4,55 & 4,43 & 0,0005 & 0,3217 & 0,0458 & 13,3 \\
\hline PB & $0,51 c$ & $0,72 \mathrm{a}$ & $0,64 \mathrm{ab}$ & $0,56 \mathrm{bc}$ & 0,61 & 0,59 & 0,0002 & 0,1739 & 0,0663 & 11,7 \\
\hline $\mathrm{EE}$ & 0,25 & 0,26 & 0,30 & 0,27 & 0,27 & 0,26 & 0,0661 & 0,2199 & 0,1348 & 13,7 \\
\hline FDNcp & 2,38 & 2,69 & 2,42 & 2,70 & 2,58 & 2,52 & 0,1353 & 0,3669 & 0,9997 & 15,9 \\
\hline CNF & 1,23 & 1,76 & 1,43 & 0,75 & 1,22 & 1,36 & $<0,0001$ & 0,0583 & 0,0006 & 14,7 \\
\hline NDT & 2,63 & 3,57 & 3,10 & 3,00 & 3,03 & 3,12 & 0,0981 & 0,6261 & 0,2598 & 20,1 \\
\hline \multicolumn{11}{|c|}{ Consumo (g/kg PV) } \\
\hline MS & $1,49 b$ & $2,21 \mathrm{a}$ & $1,67 \mathrm{~b}$ & $1,54 b$ & 1,67 & 1,78 & 0,0002 & 0,3496 & 0,2098 & 14,1 \\
\hline FDNcp & $0,81 b$ & $1,06 a$ & $0,84 a b$ & 0,96ab & 0,90 & 0,94 & 0,0299 & 0,7046 & 0,7246 & 18,9 \\
\hline \multicolumn{11}{|c|}{ Consumo (g/kgPV $\left.{ }^{0,75}\right)$} \\
\hline MS & $61,65 b$ & $88,22 \mathrm{a}$ & $68,49 \mathrm{~b}$ & $62,88 \mathrm{~b}$ & 68,78 & 71,84 & 0,0001 & 0,5394 & 0,1224 & 12,3 \\
\hline
\end{tabular}

MS: matéria seca; MO: matéria orgânica; PB: proteína bruta; EE:= extrato etéreo; FDN: fibra em detergente neutro; CNF: carboidratos não fibrosos; CT: carboidratos totais; NDT: nutrientes digestíveis totais.

Médias, na linha, seguidas de letras distintas diferem entre si $(\mathrm{P}<0,05)$ pelo teste Tukey.

A teobromina (3,7 dimetilxantina), fator antinutricional encontrado sobretudo em produtos de cacau, tem ação diurética (Alves e Bragagnolo, 2002). No presente trabalho, ao verificar o volume urinário dos animais que receberam dietas com subproduto de cacau, observou-se que, no primeiro período $(17,82 \mathrm{~mL} / \mathrm{kg}$ de $\mathrm{PV})$, os animais urinaram $38,4 \%$ a mais do que no segundo período, independentemente da porcentagem de inclusão na dieta, e que, na inclusão de $30 \%(16,67 \mathrm{~mL} / \mathrm{kg}$ de PV) deste subproduto, urinaram $18,8 \%$ a mais, independentemente do período.
Houve interação $(\mathrm{P}<0,05)$ fonte versus porcentagem de inclusão do subproduto na dieta quanto ao consumo de MS, MO e CNF (Tab. 4). Na inclusão de $30 \%$ de subprodutos agrícolas e agroindustriais, os animais consumiram mais $(\mathrm{P}<0,05) \mathrm{MS}$ e MO com as dietas com farelo de glúten de milho em relação às dietas com os subprodutos cacau, mandioca-casca e mandiocacaule, e os consumos com estes subprodutos não diferiram entre si $(\mathrm{P}>0,05)$.

Tabela 4. Consumo de matéria seca, matéria orgânica e carboidratos não fibrosos para dietas com diferentes fontes e proporções de inclusão de subprodutos

\begin{tabular}{|c|c|c|c|c|}
\hline \multirow{2}{*}{$\begin{array}{c}\text { Inclusão } \\
\text { (\%) }\end{array}$} & \multicolumn{4}{|c|}{ Subproduto } \\
\hline & Cacau & $\begin{array}{c}\text { Farelo } \\
\text { de glúten }\end{array}$ & $\begin{array}{l}\text { Mandioca- } \\
\text { casca }\end{array}$ & $\begin{array}{l}\text { Mandioca- } \\
\text { caule }\end{array}$ \\
\hline \multicolumn{5}{|c|}{ Matéria seca, kg/dia } \\
\hline 10 & 4,33 & 5,07 & 4,96 & 4,90 \\
\hline 30 & $4,40 \mathrm{~b}$ & $6,22 a$ & $4,61 \mathrm{~b}$ & $3,76 \mathrm{~b}$ \\
\hline \multicolumn{5}{|c|}{ Matéria orgânica, kg/dia } \\
\hline 10 & 3,97 & 4,83 & 4,73 & 4,66 \\
\hline 30 & $3,87 \mathrm{~b}$ & $6,07 a$ & $4,27 \mathrm{~b}$ & $3,51 \mathrm{~b}$ \\
\hline \multicolumn{5}{|c|}{ Carboidratos não fibrosos, kg/dia } \\
\hline 10 & 1,12 & $1,28 \mathrm{~B}$ & 1,49 & 0,96 \\
\hline 30 & $1,35 \mathrm{~b}$ & $2,26 \mathrm{aA}$ & $1,36 \mathrm{~b}$ & $0,53 \mathrm{c}$ \\
\hline
\end{tabular}

Médias seguidas de letras distintas, minúsculas na linha e maiúsculas na coluna, diferem entre si $(\mathrm{P}<0,05)$. 
O mesmo fato foi observado quanto ao consumo de CNF em dietas com farelo de glúten de milho em relação aos demais. O consumo dos animais que receberam subproduto cacau ou mandiocacasca foi semelhante $(\mathrm{P}>0,05)$, mas diferiu $(\mathrm{P}<0,05)$ dos que receberam dietas com mandioca-caule, consequência da baixa concentração de CNF (12,2\% na MS) na dieta.

Dentro de cada fonte do subproduto, houve interferência $(\mathrm{P}<0,05)$ da porcentagem de inclusão nas dietas com farelo de glúten de milho: com 30\% de inclusão, os animais consumiram, aproximadamente, $76 \%$ mais $\mathrm{CNF}$ do que na de $10 \%$, devido à maior concentração de CNF em comparação à silagem de milho.

A fonte do subproduto influenciou $(\mathrm{P}<0,05)$ a digestibilidade do EE e CNF, independentemente da porcentagem de inclusão dos subprodutos na dieta (Tab. 5). A digestibilidade do EE foi menor $(\mathrm{P}<0,05)$ para as dietas com farelo de glúten de milho, e a digestibilidade com os demais subprodutos não diferiram entre si $(\mathrm{P}>0,05)$.

Tabela 5. Coeficientes de digestibilidade e nutrientes digestíveis totais em função da fonte (S) e da proporção (N) de inclusão de subprodutos à dieta

\begin{tabular}{|c|c|c|c|c|c|c|c|c|c|c|}
\hline \multirow[b]{2}{*}{ Item } & \multicolumn{4}{|c|}{ Subproduto } & \multicolumn{2}{|c|}{ Inclusão (\%) } & \multicolumn{3}{|c|}{ Valor P } & \multirow[b]{2}{*}{$\begin{array}{l}\text { CV } \\
(\%)\end{array}$} \\
\hline & Cacau & $\begin{array}{c}\text { Farelo } \\
\text { de glúten }\end{array}$ & $\begin{array}{c}\text { Mandioca- } \\
\text { casca }\end{array}$ & $\begin{array}{c}\text { Mandioca- } \\
\text { caule }\end{array}$ & 10 & 30 & S & $\mathrm{N}$ & SxN & \\
\hline MS & 53,04 & 55,85 & 57,08 & 55,26 & 55,70 & 54,91 & 0,4252 & 0,6847 & 0,1155 & 8,5 \\
\hline MO & 55,09 & 60,52 & 60,65 & 59,53 & 59,68 & 58,22 & 0,1412 & 0,3468 & 0,0328 & 8,1 \\
\hline PB & 58,82 & 75,66 & 68,96 & 64,40 & 68,93 & 64,98 & 0,1361 & 0,3982 & 0,8891 & 17,4 \\
\hline $\mathrm{EE}$ & $92,58 a$ & 84,69b & $93,32 a$ & $92,28 a$ & 92,31 & 89,13 & $<0,0001$ & 0,0009 & 0,3572 & 2,1 \\
\hline FDNcp & 52,42 & 48,82 & 46,42 & 52,13 & 50,56 & 49,34 & 0,5950 & 0,6648 & 0,5868 & 19,5 \\
\hline CNF & $46,09 b$ & $75,78 a$ & $68,24 a$ & $67,27 a$ & 64,06 & 63,75 & 0,0127 & 0,3333 & 0,4739 & 8,4 \\
\hline NDT & 58,83 & 63,20 & 64,42 & 64,23 & 63,14 & 62,20 & 0,4634 & 0,8046 & 0,1588 & 7,9 \\
\hline
\end{tabular}

MS; matéria seca; MO; matéria orgânica; PB: proteína bruta; EE: extrato etéreo; FDN: fibra em detergente neutro; CNF: carboidratos não fibrosos; CT: carboidratos totais; NDT: nutrientes digestíveis totais.

Médias, na linha, seguidas de letras distintas diferem entre si $(\mathrm{P}<0,05)$ pelo teste Tukey.

A digestibilidade dos $\mathrm{CNF}$ foi menor $(\mathrm{P}<0,05)$ para as dietas com o subproduto cacau, e entre a dos demais subprodutos não houve diferença $(\mathrm{P}>0,05)$. Silva et al. (2005), ao avaliarem a digestibilidade dos nutrientes de cabras lactantes, não observaram diferenças na digestibilidade dos CNF nas inclusões de 9,23 e 18,47\% de farelo de cacau no concentrado e encontraram valores de 82,2 e $79,9 \%$, respectivamente.

Houve efeito $(\mathrm{P}<0,05)$ da porcentagem de inclusão dos subprodutos na digestibilidade do $\mathrm{EE}$, independentemente da fonte do subproduto na dieta. A inclusão de $10 \%$ de subproduto proporcionou maior $(\mathrm{P}<0,05)$ aproveitamento desse componente.

Houve interação $(\mathrm{P}<0,05)$ fonte versus porcentagem de inclusão do subproduto agrícola na dieta quanto à digestibilidade da MO (Tab. 6). $\mathrm{Na}$ inclusão de $30 \%$ de subprodutos, entre os animais que consumiram dietas com farelo de glúten de milho, a $(\mathrm{P}<0,05)$ digestibilidade da MO foi mais alta em relação às dietas com o subproduto cacau, e as digestibilidades com as dietas com mandioca-casca ou mandioca-caule não diferiram $(\mathrm{P}>0,05)$ das demais. Além do fator antinutricional (teobromina) que limita o aproveitamento da MO em dietas com o subproduto cacau, outros fatores adicionais poderiam estar relacionados à baixa disponibilidade da PB (PIDA de 7,9\% MS) aos microrganismos ruminais e, também, à maior taxa de passagem desse subproduto, já que a pequena granulometria poderia reduzir seu tempo de permanência no trato gastrintestinal.

O coeficiente de digestibilidade do NDT de farelo de glúten de milho, 78,2\%, foi, aproximadamente, $17 \%$ acima do valor observado por Magalhães (2007) para silagem de milho (67\%) e próximo do valor observado por Rocha Junior et al. (2003), 75,6\% (Tab. 7), enquanto a mandioca-casca, a mandioca-caule e o subproduto do cacau apresentaram valores energéticos de 10, 19 e 38\% abaixo do observado por Magalhães (2007) para silagem de milho. 
Tabela 6. Digestibilidade da matéria orgânica (\%) para dietas com diferentes fontes e níveis de inclusão de subproduto

\begin{tabular}{lcccc}
\hline \multirow{2}{*}{$\begin{array}{l}\text { Nível } \\
(\%)\end{array}$} & Cacau & Farelo de glúten & Mandioca-casca & Mandioca-caule \\
\cline { 2 - 5 } & 60,10 & 57,28 & 61,94 & 59,43 \\
10 & $50,09 \mathrm{~b}$ & $63,77 \mathrm{a}$ & $59,36 \mathrm{ab}$ & $59,64 \mathrm{ab}$ \\
\hline
\end{tabular}

Médias, na linha, seguidas de letras distintas diferem entre si $(\mathrm{P}<0,05)$.

Tabela 7. Coeficiente de digestibilidade, em \%, dos nutrientes e nutrientes digestíveis total de subprodutos

\begin{tabular}{lcccc}
\hline Item & Cacau & Farelo de glúten & Mandioca-casca & Mandioca-caule \\
\hline PB & 13,11 & 68,83 & 59,74 & 51,06 \\
EE & 82,00 & 64,71 & 82,77 & 85,83 \\
FDNcp & 17,56 & 56,65 & 35,28 & 66,69 \\
CNF & 64,90 & 98,54 & 37,15 & 25,80 \\
NDT & 41,23 & 78,19 & 60,30 & 54,37 \\
\hline
\end{tabular}

PB: proteína bruta; EE: extrato etéreo; FDN: fibra em detergente neutro; CNF: carboidratos não fibrosos; NDT: nutrientes digestíveis totais.

O subproduto do cacau é originado de um processo em que a semente tem que ser aquecida a temperaturas que variam de 120 a $150^{\circ} \mathrm{C}$ por até 120 minutos, e isto pode ter influenciado no alto valor de PIDA (7,9\% MS), na baixa proteína bruta digestível (PBd $=1,9 \%$ na MS). Além disso, foi observado, pelas sobras, que os animais tinham pouca preferência por esse subproduto, assim como foi observado por Silva et al. (2005). Todos esses fatores provocaram desbalanceamento proteico das dietas com o subproduto cacau e, possivelmente, interferiram na população microbiana, tanto quantitativamente como qualitativamente, para degradar a FDN das dietas com este subproduto.
A fonte de subprodutos não influenciou $(\mathrm{P}>0,05)$ nas excreções urinárias - derivados de purinas totais, purinas absorvidas, nitrogênio microbiano e eficiência microbiana -, independentemente da porcentagem de inclusão do subproduto na dieta (Tab. 8).

Os valores de eficiência microbiana obtidos para as dietas, independentemente da proporção de inclusão do subproduto, e os valores observados em cada proporção de inclusão, independentemente da fonte de subproduto, foram de 122,94g PBmic/kg de NDT, enquanto o valor médio sugerido por Valadares Filho et al. (2006) foi de 120g PBmic/kg de NDT, como referência a zebuínos em condições tropicais.

Tabela 8. Excreções urinárias de compostos nitrogenados e eficiência microbiana em função da fonte (S) e dos níveis de inclusão (N) do subproduto nas dietas

\begin{tabular}{|c|c|c|c|c|c|c|c|c|c|c|}
\hline \multirow[b]{2}{*}{ Item } & \multicolumn{4}{|c|}{ Subproduto } & \multicolumn{2}{|c|}{ Inclusão (\%) } & \multicolumn{3}{|c|}{ Valor P } & \multirow[b]{2}{*}{$\begin{array}{l}\text { CV } \\
\text { (\%) }\end{array}$} \\
\hline & Cacau & $\begin{array}{c}\text { Farelo } \\
\text { de glúten }\end{array}$ & $\begin{array}{c}\text { Mandioca- } \\
\text { casca }\end{array}$ & $\begin{array}{c}\text { Mandioca- } \\
\text { caule }\end{array}$ & 10 & 30 & S & $\mathrm{N}$ & $x N$ & \\
\hline $\mathrm{DP}^{1}$ & 94,71 & 109,63 & 110,30 & 103,72 & 104,08 & 105,10 & 0,1640 & 0,7207 & 0,5697 & 19,7 \\
\hline Pabs $^{1}$ & 79,65 & 99,84 & 98,19 & & 90,68 & 93,71 & 0,1290 & 0,4932 & 0,6203 & 26,4 \\
\hline $\mathrm{Nmic}^{2}$ & 57,91 & 72,59 & 71,39 & 66,23 & 65,93 & 68,13 & 0,1290 & 0,4932 & 0,6203 & 26,4 \\
\hline Efic $^{3}$ & 126,53 & 117,07 & 119,47 & 128,69 & 123,09 & 122,79 & 0,8812 & 0,7623 & 0,5915 & 26,7 \\
\hline
\end{tabular}

1: mmol/dia; 2: g/dia; 3: g PBmic/kg de NDT consumido; DP: derivados de purina; Pabs: purinas absorvidas; Nmic: nitrogênio microbiano; Efic: eficiência microbiana.

Médias, na linha, seguidas de letras distintas diferem entre si $(\mathrm{P}<0,05)$ pelo teste Tukey. 
A proporção de inclusão também não afetou $(\mathrm{P}>0,05)$ as variáveis apresentadas na Tab. 8, independentemente da fonte do subproduto na dieta.

A fonte do subproduto influenciou $(\mathrm{P}<0,05)$ a ingestão ( $\mathrm{g} /$ dia e $\mathrm{g} / \mathrm{kg} \mathrm{PV}^{0,75}$ ), a excreção nas fezes $\left(\mathrm{g} / \mathrm{kg} \mathrm{PV}^{0,75}\right)$ e na urina $\left(\mathrm{g} / \mathrm{kg} \mathrm{PV}^{0,75}\right.$ e g/dia) dos compostos nitrogenados e o balanço de $\mathrm{N}$ (g/dia e g/kg CMS), independentemente da porcentagem de inclusão do subproduto na dieta (Tab. 9). Os animais que receberam dietas com farelo de glúten de milho consumiram mais $\mathrm{N}$ (g/dia) $(\mathrm{P}<0,05)$ do que os que consumiram dietas com o subproduto cacau ou mandiocacaule. Os que consumiram dietas com mandiocacasca não diferiram ( $\mathrm{P}>0,05)$, quanto ao consumo de $\mathrm{N}$, dos que consumiram dietas com farelo de glúten ou mandioca-caule, e também não houve diferenças $(\mathrm{P}>0,05)$ de consumo entre as dietas com o subproduto cacau e a mandiocacaule.

Para consumo de $\mathrm{N}$ (g/kg $\left.\mathrm{PV}^{0,75}\right)$, os maiores $(\mathrm{P}<0,05)$ valores foram observados entre os animais que consumiram dietas com 0 subproduto cacau, em relação àqueles que se alimentaram de farelo de glúten de milho ou de mandioca-casca. Os animais que receberam dieta com mandioca-caule não diferiram $(\mathrm{P}>0,05)$, quanto ao consumo de $\mathrm{N}$, dos que consumiram dietas com subproduto cacau ou mandioca-casca e, também, não houve diferenças $(\mathrm{P}>0,05)$ entre os que se alimentaram com farelo de glúten, mandioca-casca ou mandioca-caule para consumo de $\mathrm{N}$.

Tabela 9. Compostos nitrogenados ingeridos $(\mathrm{N})$, excretados, e balanço de $\mathrm{N}(\mathrm{BN})$ para dietas com diferentes fontes (S) e níveis $(\mathrm{N})$ de inclusão de subproduto

\begin{tabular}{|c|c|c|c|c|c|c|c|c|c|c|}
\hline \multirow[b]{2}{*}{ Item } & \multicolumn{4}{|c|}{ Subproduto } & \multicolumn{2}{|c|}{$\begin{array}{c}\text { Inclusão } \\
(\%)\end{array}$} & \multicolumn{3}{|c|}{ Valor P } & \multirow[b]{2}{*}{$\begin{array}{l}\text { CV } \\
(\%)\end{array}$} \\
\hline & Cacau & $\begin{array}{c}\text { Farelo } \\
\text { de } \\
\text { glúten }\end{array}$ & $\begin{array}{c}\text { Mandioca } \\
- \\
\text { Casca }\end{array}$ & $\begin{array}{c}\text { Mandioca } \\
- \\
\text { Caule }\end{array}$ & 10 & 30 & S & $\mathrm{N}$ & $\mathrm{S} \times \mathrm{N}$ & \\
\hline \multicolumn{11}{|c|}{$\mathrm{N}$ ingerido } \\
\hline \multirow{3}{*}{ g/dia } & 81,25 & & & & 98,5 & 94,8 & 0,000 & 0,173 & 0,066 & 11,6 \\
\hline & C & $114,74 a$ & 101,64ab & $89,00 \mathrm{bc}$ & 1 & 1 & 2 & 9 & 3 & 7 \\
\hline & & & & & & & 0,000 & 0,421 & 0,231 & 15,7 \\
\hline \multirow[t]{2}{*}{$\mathrm{g} / \mathrm{kgPV}^{0,75}$} & $0,89 a$ & $0,56 c$ & $0,69 b c$ & $0,80 \mathrm{ab}$ & 0,72 & 0,75 & 6 & 8 & 6 & 0 \\
\hline & & & & N recal & 35,4 & 33,2 & 0,184 & 0,890 & 0,185 & \\
\hline \multirow[t]{2}{*}{ g/dia } & 38,64 & 34,07 & 31,63 & 33,21 & 9 & 9 & 0 & 8 & 3 & 24,4 \\
\hline & & & & & & & 0,037 & 0,760 & 0,340 & \\
\hline \multirow[t]{2}{*}{ g/kgPV ${ }^{0,75}$} & $1,90 \mathrm{a}$ & $2,65 a$ & $2,28 \mathrm{a}$ & $2,11 \mathrm{a}$ & 2,17 & 2,30 & 4 & 5 & 1 & 29,2 \\
\hline & 31,22 & & & $\mathrm{Nu}$ & 42 1 & 393 & $0 \Omega 40$ & 0406 & 0709 & \\
\hline \multirow[t]{2}{*}{ g/dia } & b & $37,52 \mathrm{ab}$ & $51,99 a$ & 42,17ab & 4 & 1 & 2 & 3 & 2 & 29,3 \\
\hline & & & & & & & 0,009 & 0,890 & 0,690 & \\
\hline \multirow[t]{3}{*}{ g/kgPV ${ }^{0,75}$} & $2,43 a$ & $1,75 \mathrm{ab}$ & $1,44 b$ & $1,69 \mathrm{~b}$ & 1,85 & 1,80 & 3 & 1 & 8 & 25,7 \\
\hline & & & & $\mathrm{BN}$ & & & & & & \\
\hline & 11,38 & & & & 23,8 & 22,2 & 0,000 & 0,434 & 0,076 & \\
\hline \multirow[t]{2}{*}{ g/dia } & b & $49,15 a$ & $18,02 b$ & $13,62 b$ & 8 & 1 & 3 & 6 & 9 & 55,0 \\
\hline & & & & & & & 0,909 & 0,627 & 0,444 & 281 , \\
\hline \multirow[t]{2}{*}{$\mathrm{g} / \mathrm{kgPV}^{0,75}$} & 5,32 & 1,61 & 3,55 & 4,21 & 2,80 & 4,54 & 2 & 1 & 8 & 5 \\
\hline & & & & & & & 0,005 & 0,240 & 0,268 & \\
\hline g/kgCMS & $2,13 b$ & $8,65 a$ & $3,65 b$ & $2,40 \mathrm{~b}$ & 4,78 & 3,64 & 1 & 4 & 1 & 73,8 \\
\hline
\end{tabular}

Médias, na linha, seguidas de letras distintas diferem entre si $(\mathrm{P}<0,05)$ pelo teste Tukey. 
A excreção urinária de $\mathrm{N}$, quando expressa em $\mathrm{g} /$ dia, foi maior $(\mathrm{P}<0,05)$ para os animais alimentados com mandioca-casca em relação aos alimentados com subproduto cacau, e estas duas dietas não diferiram $(\mathrm{P}>0,05)$ das dietas com farelo de glúten de milho ou mandioca-caule, independentemente da porcentagem de inclusão dos subprodutos às dietas. A excreção urinária de $\mathrm{N}$, quando expressa em $\mathrm{g} / \mathrm{kgPV}^{0,75}$, foi maior $(\mathrm{P}<0,05)$ para os animais alimentados com 0 subproduto cacau em relação aos que consumiram dietas com mandioca-casca ou mandioca-caule, e essas duas não diferiram $(\mathrm{P}>0,05)$ das dietas com farelo de glúten de milho, independentemente da proporção de inclusão dos subprodutos.

O balanço de nitrogênio, quando expresso em $\mathrm{g} /$ dia, foi influenciado $(\mathrm{P}<0,05)$ pela fonte do subproduto. As dietas com farelo de glúten de milho resultaram em valores mais altos que as dietas com os outros subprodutos, independentemente da proporção de inclusão dos subprodutos nas dietas. Quando expresso em $\mathrm{g} / \mathrm{kg}$ de CMS, houve maior balanço de nitrogênio $(\mathrm{P}<0,05)$ nas dietas com farelo de glúten de milho em relação às dietas com os demais subprodutos, independentemente da proporção de inclusão dos subprodutos.

O maior balanço de $\mathrm{N}(\mathrm{P}<0,05)$ para as dietas com farelo de glúten de milho pode estar relacionado à melhor sincronização da degradação entre proteína e energia dessa fonte de subproduto e, também, aos teores de CNF dessas dietas (29,8 e 33,9\% na MS). Segundo Clark et al. (1992), a disponibilidade de energia e $\mathrm{N}$ são fatores limitantes para o crescimento microbiano ruminal.

Independentemente da fonte e do nível de subproduto nas dietas, não se observou valor negativo para o $\mathrm{BN}$, indicando que houve retenção de proteína no organismo animal e que o consumo de proteína atendeu às exigências proteicas dos animais.

\section{CONCLUSÕES}

O farelo de glúten de milho e a mandioca-casca podem substituir, parcialmente, os concentrados energéticos, sem prejuízos do consumo, digestibilidade, eficiência microbiana e retenção de nitrogênio. O subproduto de mandioca-caule tem potencial para substituir, parcialmente, volumosos nas dietas de ruminantes. $\mathrm{O}$ subproduto de cacau apresenta limitações de uso em dietas de ruminantes.

O autor S.C. Valadares Filho é coordenador e os autores J.A.G. Azevêdo; R.F.D. Valadares são membros do INCT em Ciência Animal.

\section{REFERÊNCIAS BIBLIOGRÁFICAS}

ALVES, A.B.; BRAGAGNOLO, N. Determinação simultânea de teobromina, teofilina e cafeína em chás por cromatografia líquida de alta eficiência. Rev. Bras. Cienc. Farmac., v.38, p.237-243, 2002.

CARVALHO, J.L.H. Uso da parte aérea da mandioca na alimentação animal. In: CONGRESSO BRASILEIRO DE MANDIOCA, 3., 1983, Brasília. Anais...Brasília, 1983. p.13-38.

CEREDA, M.P. Valorização de resíduos como forma de reduzir custo de produção. In: CONGRESSO LATINO-AMERICANO DE RAÍZES TROPICAIS, 1., 1996, São Pedro. Anais... São Pedro, 1996. p.25-43.

CHEN, X.B.; GOMES, M.J. Estimation of microbial protein supply to sheep and cattle based on urinary excretion of purine derivatives - an overview of technical details (Occasional publication). INTERNATIONAL FEED RESOURCES UNIT. Aberdeen: Rowett Research Institute, 1992. 21p.

CLARK, J.H.; KLUSMEYER, T.H.; CAMERON, M.R. Microbial protein syntesis and flows of nitrogen fractions to the duodenum of dairy cows. J. Dairy Sci., v.75, p.2304-2323, 1992.

FUJIHARA, T.; ØRSKOV, E.R.; REEDS, P.J. et al. The effect of protein infusion on urinary excretion of purine derivatives in ruminants nourished by intragastric nutrition. J. Agric. Sci., v.109, p.7-12, 1987.

GRANDE, P.A.; ALCALDE, C.R.; MACEDO, F.A.F. et al. Desempenho e características de carcaça de cabritos da raça Saanen recebendo rações com farelo de glúten de milho e/ou farelo de soja. Acta Scient., v.25, p.315-321, 2003. 
HALL, M.B. Neutral Detergent-Soluble Carbohydrates. Nutritional Relevance and Analysis. Gainesville: University of Florida, 2000.

LASSITER, J.W.; EDWARDS Jr., H.M. Animal nutrition. Reston, VA:Virginia: Reston Publishing, 1982. p.339-340.

LICITRA, G.; HERNANDEZ, T.M.; VAN SOEST, P.J. Standardization of procedures for nitrogen fractionation of ruminant feeds. Anim. Feed Sci. Technol., v.57, p.347-358, 1996.

MACEDO, L.G.P.; DAMASCENO, J.C.; MARTINS, E.N. et al. Substituição do farelo de soja pela farinha de glúten de milho na alimentação de cabras leiteiras. Rev. Bras. Zootec., v.32, p.992-1001, 2003.

MAGALHÃES, K.A. Tabelas brasileiras de composição de alimentos, determinação $e$ estimativa do valor energético de alimentos para bovinos. 2007. 263p. Tese (Doutorado) Universidade Federal de Viçosa, Viçosa, MG.

MERTENS, D.R. Analysis of fiber in feeds and its use in feed evaluation and ration formulation. In: SIMPÓSIO INTERNACIONAL DE RUMINANTES, 1992, Lavras. Anais... Lavras: SBZ, 1992. p.1-32.

OFFICIAL methods of analysis, 15.ed. Washington: AOAC, 1990.

PIRES, A.J.V.; VIEIRA, V.F.; SILVA, F.F. et al. Níveis de farelo de cacau (Theobroma cacao) na alimentação de bovinos. Rev. Electr. Vet., v.6, p.1-10, 2005.
ROCHA JÚNIOR, V.R.; VALADARES FILHO, S.C.; BORGES, A.M. et al. Estimativa do valor energético dos alimentos e validação das equações propostas pelo NRC 2001. Rev. Bras. Zootec., v.32, p.480-490, 2003.

SILVA, H.G.O.; PIRES, A.J.V.; SILVA, F.F. et al. Digestibilidade aparente de dietas contendo farelo de cacau ou torta de dendê em cabras lactantes. Pesq. Agropec. Bras., v.40, p.405-411, 2005.

SILVA, J.F.C.; LEÃO, M.I. Fundamentos da nutrição de ruminantes. Piracicaba, Livroceres, 1979. 380p.

SODRÉ, G.A. Resíduos regionais usados como substratos na região sul da Bahia. In: ENCONTRO NACIONAL SOBRE SUBSTRATOS PARA PLANTAS. 6., 2008, Fortaleza. Anais... Embrapa Agroindústria Tropical, UFC e SEBREA/CE, 2008.

VALADARES FILHO, S.C.; PAULINO, P.V.R.; MAGALHÃES, K.A. (Eds.) Exigências nutricionais de zebuínos e tabelas de composição de alimentos BR-Corte. 1.ed. Viçosa, MG: UFV, 2006. 142p.

VAN SOEST, P.J.; ROBERTSON, J.B. Analysis of forages and fibrous foods. Ithaca, NY: Cornell University, 1985. 